\title{
TITLE:
}

\section{Coordination, specialization, and incentives in product development organization}

\section{$\operatorname{AUTHOR}(S)$ :}

Itoh, Hideshi

\section{CITATION:}

Itoh, Hideshi. Coordination, specialization, and incentives in product development organization. 京都大学経済学部Working Paper 1992, 17

ISSUE DATE:

1992-09

URL:

http://hdl.handle.net/2433/37912

RIGHT: 
COORDINATION, SPECIALIZATION, AND INCENTIVES

IN PRODUCT DEVELOPMENT ORGANIZATION

by

Hideshi Itoh

Faculty of Economics

Kyoto University

Faculty of Economics,

Kyoto University, Kyoto, 606 JAPAN 
COORDINATION, SPECIALIZATION, AND INCENTIVES

IN PRODUCT DEVELOPMENT ORGANIZATION

by

Hideshi Itoh

Faculty of Economics

Kyoto University 


\title{
COORDINATION, SPECIALIZATION, AND INCENTIVES IN PRODUCT DEVELOPMENT ORGANIZATION*
}

\author{
BY \\ HIDESHI ITOH ${ }^{\dagger}$ \\ First Version: August 1991 \\ This Version: September 1992
}

\begin{abstract}
Recent empirical research on product development in the world auto industry indicates that projects with less specialized task assignments and "stronger" (heavyweight) project managers have better performance. The best project organization thus appears to have characteristics of both centralized and decentralized coordination. The shift to such organizational form has been observed worldwide in the 1980s and is expected to continue in the 1990s. The purpose of the paper is to seek to understand this observation from the viewpoints of information economics. It is argued that the heavyweight project manager system performs better not just because of its strong coordination capability but because of the centralized responsibility for concept creation and the centralized strong incentive system. It is shown that under this system, project participants are optimally induced to have broader task assignments: Strong product managers and the low levels of specialization appear in conjunction. These features result from the growing significance of "product integrity" more than functionality of a few dimensions of the new product.
\end{abstract}

* Earlier versions of the paper were presented at the conference on "Japan in a Global Economy-A European Perspective" held at the Stockholm School of Economics, 5-6 September 1991, and at the Mitsubishi International Conference on "New Imperatives for Managing in Revolutionary Change," held in Ito City, Japan, 3-6 September, 1992. I would like to thank Hiroyuki Itami and John McMillan for helpful comments and the conference participants for helpful discussions.

$\dagger$ Faculty of Economics, Kyoto University, Sakyō-ku, Kyoto 606-01, Japan. Tel: +81-75753-3423, Fax: +81-75-751-1532, Bitnet: e52832@jpnkudpc 


\section{Introduction}

How does an effective organization form for developing complicated new products look like? Recent empirical research in the world auto industry provides an interesting answer: project organizations with broad task assignments among engineers and powerful product managers (called "heavyweight" product managers) have better performance in product development (Clark, Chew, and Fujimoto, 1987; Clark and Fujimoto, 1991; Womack, Jones, and Roos, 1990). The purpose of the paper is to seek to understand this seemingly paradoxical observation.

In order to design a new car, numerous decisions on the target market of consumers, specifications, appearance, performance, and so on, must be made. Furthermore, various dimensions of the car must fit well together: decisions must be coordinated. Failing to attain the proper coordination among various attributes of the car will be very costly. One key role of a product manager is certainly to ensure coordination. The heavyweight product manager system in which a product manager is responsible for all aspects of the project and has strong influence over participating engineers will probably achieve more effective centralized coordination among engineers. However, then why do engineers under the heavyweight product manager system are less specialized? Similarly, if engineers perform multiple tasks together so that they can share knowledge easily and coordinate their activities autonomously, the need for centralized coordination by the product manager should be reduced.

Given the empirical results, I will discuss two types of reasons why this combination of a small degree of specialization with a strong product managers is optimal. The first scenario looks at the product manager's role as a strategic business decision maker. As Clark and Fujimoto (1991) argue, one of the most important roles of the heavyweight product manager is to create and communicate a core concept of the new product that matches consumer expectations. He requires allocating his limited attention to information gathering about consumer needs and to communication of the concept with engineers, besides to already complex tasks of coordination across detailed functional activities and components. It is usually the case that engineers are expected to have a priori information about how the details must be coordinated and implemented. Broad task assignments and job duplication further encourage interaction and communication among engineers, and enable them to attain an internally consistent combination of activities without relying much on the product manager. However, 
there are in general many combination that are internally coherent and not all of them are globally optimal: Technological progress or changing customer expectations change the most effective combination discontinuously. Creating an explicit concept and communicating it with engineers ensure that the combination chosen by the engineers is globally optimal. Today the integrity of the car and its match to ambiguous and changing customer expectations appear to be more important than individual functional performances. The problem that lateral coordination may reach a combination which is internally consistent but not the best one is more serious. The product manager should hence attend more to concept creation and infusion, and less to detailed engineering coordination per se. The result is that less specialized (for the purpose of lateral coordination among engineers) while more centralized (in terms of business decision making, i.e., concept creation) product development organizations perform better.

The second story focuses on the incentive dimension of product development. Another important role of the heavyweight product manager that is absent in other types of organizations is to provide project members with strong incentives to cooperate for success of the project. Although I do not offer any answer to the question of how the product manager, without formal authority, can influence engineers, I will argue that, provided that strong incentives can be provided, the heavyweight product manager will (rationally) induce participating engineers to perform a wide range of tasks with job duplication with others. The key factors are team production and complementarities. Complementarities across tasks and engineers are inherent in complex product development such as designing a new car: As an engineer does more of an activity, his marginal returns to doing more of any other activity as well as the other engineers' marginal returns to the first activity increase. This feature not only creates the possibility of coordination failure discussed above, but also makes the performance measurement at each task difficult. Then the organization can reduce the costs of inducing engineers to work hard for the success of the project, by increasing the number of tasks performed by each individual engineer and creating joint responsibility so that some tasks are performed jointly by several engineers. Without the heavyweight product manager, broadening task assignments would increase the incentive costs.

These two points are also important in understanding the internal organization of Japanese firms in general. It is often said that in the stylized Japanese firm more responsibilities are delegated to workers than in the Western counterpart, e.g., coordination tasks, responses to 
emergent events, and so on, and there is some systematic empirical evidence as well (see Aoki (1988) and Lincoln and McBride (1987) for a survey). However, one should also note that such decentralization works well only within some acceptable conditions that are set by a central unit. For example, it is the careful prior production scheduling by the central planning office and the factory engineering office that enables the horizontal coordination through "kanban" to perform fine tuning of production across horizontal shops effectively and flexibly (see Monden, 1983).

On the incentive side, Aoki (1988) summarizes my point in his First Duality Principle: In order for firms to be internally integrative and organizationally effective, either their coordination or their incentive mode needs to be hierarchical, but not both. Japanese firms tend to be less hierarchical in coordination of operation decisions while they rely on centralized incentive systems. Product development organization mainly adopted by the Japanese makers is consistent with this pattern: engineering coordination is decentralized to less specialized functional structures with intensive lateral information flow, while incentives are centralized through the heavyweight product manager. A problem of many projects in the West may be that they are decentralized both in coordination and incentives.

The rest of the paper is organized as follows. Section 2 summarizes the empirical evidence on product development in the world auto industry. Section 3 is devoted to the informal study of specialization in organizations. Then based on the discussion in Section 3, Sections 4 and 5 develop two theories of the optimal organization structure mentioned above in detail. Section 6 contains a summary and concluding remarks, with some thoughts on international differences.

\section{Empirical Findings}

Two large-scale research projects have recently reported interesting findings on product development organization. The work by Clark and Fujimoto (Clark, Chew, and Fujimoto, 1987; Clark and Fujimoto, 1991) surveyed almost all the U.S., Japanese, and European auto makers, and collected data on a number of product development projects; each engaged in development of either an entirely new model or a major model change in which over half the parts were newly designed. The regional data collected by Clark and Fujimoto revealed that 
even after adjusting differences in size and scope of projects, the average Japanese project attained better performance (significantly shorter lead time), using less engineering hours, than the average U.S. and European counterparts. They then conducted further analysis to find factors explaining this difference.

The larger scale research project by IMVP (International Motor Vehicle Project) at MIT pursued to understand a new production system called "lean system," mainly adopted by Japanese makers, in contrast to the traditional mass production system (Womack, Jones, and Roos, 1990). While this research project covered not only product development but also almost every aspect of business and transaction in the auto industry, the researchers, partly relying on the work by Clark and Fujimoto, also attempted to understand differences in performance of design methods employed by mass and lean producers.

The major finding on the relationship between product development organization and performance, due to Clark and Fujimoto, is that what they call the heavyweight product manager system attains superior performance on speed, productivity, and product quality. Clark and Fujimoto define four modes of development organization based on the differences in the degree of specialization and the power of product managers. In the traditional functional structure, engineers are relatively specialized and no individual has overall responsibility for the total product. Instead, the heads of functional divisions are responsible for the performance of their function. In the lightweight product manager system, work is still organized into functional divisions, and hence engineers belong to their functional groups and may work on other projects at a time. Their degree of specialization is similar to that found in the functional structure. The difference is that a product manager is in charge of coordinating activities among participating engineers. However, product managers are "lightweight" in several respects: Compared with functional managers, they have relatively low status within the firm; They have no direct access to working-level engineers on the project and hence only limited influence over them; The lightweight product manager is only in charge of coordination within engineering function and possibly of product planning, and has neither direct market contact nor concept responsibility.

In the heavyweight product manager system, the organization is again largely functional, and hence the product manager has no formal authority. However, the heavyweight product manager has strong direct and indirect influence across all functions and activities in the 
project, works directly with engineers, and has a status in the firm at the same as or higher rank than the heads of the functional divisions. Furthermore, the product manager in this system has direct responsibility not only for engineering coordination but also for product planning and concept creation. Participating engineers work within their functional areas as in the lightweight product manager system, while they are now more strongly oriented toward the product, and their task assignments are broader than the first two systems.

The fourth and final mode called the project execution team structure, though no maker has adopted this structure, has a group of engineers who devote all their time to the project. They leave their functional departments and the product manager now has formal authority over them. The engineers will have broader responsibilities in their functional tasks and as members of the team than any other system.

Clark and Fujimoto measure the degree of specialization by the total number of engineers and technical support personnel who were involved with the project on more than a short-term basis, and find that the relationship between the degree of specialization and performance is negative: projects with lower degrees of specialization are faster and more efficient. They also find that the heavyweight product manager system has the lower degree of specialization, though it is regarded as the one with the higher degree of integrity and coordination, than the functional structure and the lightweight product manager system. In particular, task assignments among engineers in Japanese projects tend to be broader both in breadth of activities (e.g., an engineer does both design and testing) and in range of components (e.g., an engineer does the entire door lock mechanism rather than only the door hatch). ${ }^{1}$

Clark and Fujimoto further argue that the worldwide trend of organizational change is from a purely functional structure with no product manager to a product manager system, and from lighter to heavier managers. Although many of the best performing projects were Japanese, the regional differences do not seem to be the whole story. Even within each region, the same relationship as those reported above can be observed. Although they have not controlled a size effect in comparison, "there is at least a hint in the data that the more effective projects are likely to be smaller than average, with broader assignments for participating

1 One might argue that the number of participants in the average Japanese project is smaller because Japanese auto makers rely more on their major suppliers for design and drawings for parts than the Western makers (Asanuma, 1988, 1989). Fujimoto (personal communication) told me that he and Clark adjusted this possible bias to obtain the result. 
engineers." (Clark, Chew, and Fujimoto, 1987, p. 756).

Womack et al. attribute the Japanese advantages mainly to the following four organizational factors: (i) leadership of the heavyweight product manager; (ii) the tightly knit team; (iii) highest efforts at the outset of product development; and (iv) the pursuit of multiple development activities simultaneously. By (ii) they imply that those involved in the project are much well motivated for the success of the project, compared with American organizations where a project is moved from department to department along with personnel changes at each step. In the U.S. project, the number of people involved is very small at first but grows toward the time of product launch in order to resolve problems that should have been cleared up in the beginning. The manager in the Japanese project resolves conflicts about objectives and roles at the outset. Once consensus is reached, subsequent progress is very rapid. In particular, various aspects of the project progress simultaneously, e.g., body design and die production, with an immense amount of information flows. This factor is also supported by a finding by Clark and Fujimoto: The Japanese projects showed a high degree of overlap of development activities in time, and intensive transfer of preliminary design information from upstream to downstream. The relation between the degree of overlapping and lead time was significantly negative in the Japanese data only; little relation was found in the rest of the sample.

Although little comparative research exists outside the auto industry, the implications from these findings seem to apply to today's other manufacturing industries with complex products. Based on the detailed research of several industries, the report by the MIT Commission on Industrial Productivity identifies emerging patterns of best industrial practice, which are largely consistent with the results shown above (Dertouzos et al. 1989).

It is not obvious to explain these findings from coordination purposes, particularly better performance of both more centralized (stronger product managers) and more decentralized (functionally less specialized) systems. In Sections 4 and 5, I will focus on two distinguished roles of the heavyweight product managers, concept creation and incentive supply, in order to explain these interesting observations. Before doing so, I will examine the effects of different specialization levels of engineers in a project informally in the next section, because little economic analysis on the extent of division of labor has been done. The analysis offers an important basis of my arguments to understand the optimal development organization form. 


\section{Specialization and Job Design in a Project}

According to Clark and Fujimoto, the degree of specialization in a project is smaller under one system than under another if the total number of engineers is smaller under the former system. This implies two possibilities. First, on average, an engineer in the former system performs more tasks. For example, suppose that there are four divisible tasks in a project. If firm $A$ uses four engineers each of which performs one of them without no duplication, and firm $B$ uses two engineer one of which works on two of the tasks and the other is assigned to the other two tasks, then the degree of specialization is smaller in firm $B$ than firm $A$. Note that in these firms, each task is performed by only one engineer: there is no joint responsibility. However, there is also a possibility of job duplication. Suppose that in firm $C$, two engineers jointly perform all the four tasks. Firm $C$ has a lower level of specialization than Firm $A$, while the more important difference may be that in Firm $C$ each task is performed jointly by two engineers.

These two features of lowering the level of specialization in a project have sometimes similar, sometimes different effects on the performance of the project. In the first subsection, I focus on technological issues such as coordination and economies of specialization. There I rule out incentive problems by assuming that all the participating engineers are only interested in the success of the project. The second subsection focuses on incentive issues-how the costs of providing engineers with strong incentives to cooperate for the success of the project vary with the degree of specialization.

\subsection{Coordination and specialization}

Coordination advantages: If an engineer performs more tasks, coordination is likely to be easier. For example, suppose that in the example given above, activities in the four tasks are interrelated and hence must be arranged properly. In firm $A$, specialized, independent activities at the four tasks may not be optimal for the project as a whole, and hence coordination among four engineers by some centralized unit will be necessary. In firm $B$, centralized coordination is required between two engineers, as long as each engineer there understands how his two tasks should relate with one another. In firm $C$, coordination among engineers is still needed. However, because they work jointly on all the tasks, they will be able, to some degree, to share knowledge and information and to adjust their activities without a centralized 
unit. Such lateral coordination is difficult in firm $A$ because the engineers there are isolated and specialized. If lateral coordination has some advantages over centralized, hierarchical coordination, one can conclude that firm $C$ has coordination advantages over firm $A$. For example, because engineers tend to have better information about their tasks, lateral coordination may have an advantage of utilizing such information, provided that communication is costly (see Bolton and Farrell (1990) for an economic analysis). Or in some situations, lateral coordination may be fast and flexible (see Aoki (1986; 1988, Chapter 2)).

Loss in economies of specialization: The productivity of each engineer may be higher in firm $A$ than in firms $B$ or $C$, because in firm $A$, he can concentrate on one task: If each task requires intensive attention and highly distinctive expertise, higher levels of specialization will utilize the talents and efforts of engineers more effectively. Specialization may also result in learning by doing, and increase the engineers'.productivity. Note, however, that if two tasks are interrelated such that performing one task increases the returns from the other task (two tasks are complementary) and this effect dominates the economies of specialization, then these tasks should be performed by one engineer: firm $B$ may be superior to firm $A$.

Substituting centralized coordination: The discussion given above implies that the centralized coordination among specialized members and the decentralized coordination with a small degree of specialization are substitutes: ceteris paribus, decreasing inputs from a centralized unit for coordination purposes increases the need for lateral coordination, and hence reduces the degree of specialization. Similarly, if the input by the product manager for coordinating the details of the plans increases, the degree of specialization will rise in order to pursue specialization economies more extensively. ${ }^{2}$ This reasoning being accepted, the empirical findings are puzzling. One needs to look at the roles of the heavyweight product manager in more detail.

\subsection{Incentive effects of job design}

I now consider the effects of task assignments on the engineers' incentives to perform their tasks. Suppose for a while that the four tasks are technologically independent: Activities at one task have no effect on the other tasks. This assumption excludes the technological considerations given in the preceding subsection.

2 See Itoh (1988) for an attempt to formalize this relationship between specialization and coordination systems. 
Incentives and measurement: I first assume that performance in each of the four tasks can be measured separately (possibly with noise). Then in firm $A$ and firm $B$, the performance measure of each task provides information about the effort of the engineer who is assigned to that task. However, in firm $C$, all the performance measures reflect the efforts of the two engineers: Sole responsibility has an advantage in supplying more informative performance measures than joint responsibility. Next, suppose that the four tasks differ in terms of measurability. Suppose further that performance at two of the tasks are substantially easier to measure than the others, while the former tasks are not as important as the latter in terms of its impact on the project outcome. Then if in firm $B$, each engineer is assigned to an easyto-measure task and a hard-to-measure task, a problem will arise: The engineer may allocate too much effort to the less significant but more visible task. Thus, firm $B$ cannot provide strong incentives via the performance measure at the easier-to-measure task. This problem does not occur in firm $A$. Of course, firm $B$ can remedy the problem by assigning one engineer to two easy-to-measure tasks and the other to the hard-to-measure tasks (see Holmstrom and Milgrom (1991) for the formal analysis).

The second case to be analyzed is that there are two identical signals, one of which measures the joint performance at two of the tasks, the other measures the performance at the other two tasks. Now the task assignment in firm $A$ has a measurability problem: Each performance measure reflects efforts from two engineers. They may reduce their efforts by attempting to free-ride on each other. In firm $B$ this problem can be avoided by assigning one engineer to the first two tasks and the other to the remaining two. In firm $C$, all the four tasks are performed by two engineers, and hence the measurability problem continues to exist. However, it is still possible that the task assignment in firm $C$, which is broader than that in firm $B$, can keep the effort incentives high, even without complementarities, by reducing monotonicity or boredom of performing a few tasks (see Itoh $(1991 ; 1992 \mathrm{a})$ for the formal derivation of this result).

Finally, consider the most realistic situation where task-specific performance measures are not at all available: The only measure is the total performance of the project. Assume also that firms can nevertheless impose the task assignments on engineers: For example, I assume that firm $A$ can still make each agent work on just one task. Then the degree of specialization does not affect performance measurement, while the three task assignment 
patterns will have different results in performance, depending on how tasks and engineers interrelate with each other. Obviously, the technological considerations in the previous section are important. Many engineering tasks are likely to be mutually complementary: doing more of any one task increases the marginal profitability of each other activity. The existence of complementarities will favor a small degree of specialization because of more coordination advantages and less disadvantages from the loss of specialization economies. However, there are a few other considerations.

Cooperation and incentives: Broader task assignments with job duplication as in firm $C$ can not only facilitate lateral coordination but also reduce incentive costs. Because the engineers jointly work on the tasks, it is easy to monitor each other's activity mutually. Suppose that as a result of peer monitoring, the engineers jointly make decisions concerning how to perform the tasks together. Such cooperation may be beneficial to the firm, compared with the case in which the engineers behave independently, in the sense that the engineers can be induced to work appropriately while less responsibility needs to be imposed on each engineer (see Itoh (1992a; 1992b) for the formal analysis).

Interpersonal complementarities and incentives: In product development organization, not only complementarities among tasks but also complementarities among engineers at each task may exist: Any one engineer's productivity at a task increases as the other engineers work more on that same task. This feature mitigates the measurement problem under joint responsibility, and provides job duplication with another advantage over highly specialized task assignments (Itoh, 1991).

Changing the level of specialization in a product development project has several effects. The main conclusion is that in the environments facing the automobile industry today, broadening task assignments and creating job duplication in the project have several advantages. The next two sections relate these results with the heavyweight product manager.

\section{Concept Creation and Coordination}

One distinct aspect of the successful product development organization is that the product manager has broader responsibilities, not only coordination within engineering but also 
product planning and marketing (see the findings summarized in Section 2). In particular, he is responsible for creating the concept of the new product and communicating it to designers and engineers in their languages.

The importance of product concept appears to be growing. Customers today demand not only a high level of functional performance such as fuel efficiency, noise, handling, etc. but also "product integrity" such as reliability, product image, total driving experience, etc., which must closely match ambiguous and rapidly changing consumer expectations.

However, expertise and information necessary for concept creation are not easily available in engineering groups. To improve decision making in a project, a huge amount of information must be gathered and processed. As Simon (1976) eloquently stated, even though information sources abound, capacities to process information are scare resources, and each member must allocate his limited attention/time to various information sources. Geanakoplos and Milgrom (1991) show formally that in such a circumstance, asymmetric information is unavoidable in an optimal organization: each member should have better information about some aspects of problem solving than any other member. In some cases, each member optimally limits their attention to information sources that affect his immediate operating decisions, even if the members share the goal of the project. Engineers thus specialize in gathering technological information only relevant to their local activities and are not likely to acquire important information about product concept satisfying consumer demand. The point is that engineers do not seem to have advantages in gathering information needed for creating product concept that fulfills customer expectations.

In the heavyweight product manager system, top management delegates the task of concept creation to a product manager who optimally specializes in relevant information processing. According to Clark and Fujimoto, the heavyweight product manager spends considerable time and resources for market information gathering, often not through the marketing unit but through his own staff or by direct contract with consumers (e.g., visit dealers). In the functional structure and the lightweight product manager system, top management may develop product concepts based on information from the marketing division, or may delegate the decision to marketing managers.

What are the advantages of delegating concept development to a product manager? First, every firm has a range of models, and hence it is too costly for top management to allocate 
its precious time to concept development of many products. Some degree of delegation will be inevitable. The major problem of delegating it to the market division is communication with engineers. It is not easy for marketing people to translate their concept decision into the engineers' languages. Note that most heavyweight product managers are engineers in their background. Furthermore, they can learn the languages of customers through more direct information gathering than mere use of data from the marketing division.

By realizing the role of the heavyweight product manager as a concept creator besides a coordinator, the optimality of a project organization with a small degree of specialization and a strong manager can be figured out. Although I do not have a specific model, it is possible to construct a model consistent with the story given here, which features limited managerial attention (as in Geanakoplos and Milgrom (1991)). Suppose that when product integrity becomes more important and customer expectations become more uncertain and volatile, reallocating more attention to the information sources relevant to concept creation leads to higher returns to the project. The product manager then rationally increases his attention to such data and attends less to information relevant to detailed engineering coordination. Then, the return to lateral coordination among engineers increases, and they optimally reduce their degree of specialization in order to facilitate such coordination, as I argued in the previous section. Note that many problems may have been resolved by the manager at the outset of the project as Womack et al. (1990) point out. However, there could arise later many unforseen problems in implementing the details, and the less specialized structure has advantages of solving the problems more quickly and flexibly. The result is that as product integrity becomes more important, more centralized (in terms of concept creation and its related information gathering) and more decentralized (in terms of engineering coordination, and hence less specialized) product organization performs better.

This simple explanation depends on several assumptions. First of all, each party has only limited attention and hence must determine how to allocate it to various activities. This assumption is what Simon (1976) have emphasized. Second, the marginal returns to the product manager's input into concept creation increases as the understanding of the product integrity and its match with consumer expectations become more critical. To grasp this relation, it is important to realize that designing a new car is a problem with design attributes and innovative attributes (see Milgrom and Roberts (1992, Chapter 4)). Diverse activities 
by engineers are likely to exhibit mutual complementarities: doing more of any one activity increases the marginal profitability of each other activity in the engineering group. Then the product development project has design attributes: (i) the cost of failing to fit the details together is very high, and hence reaching an internally consistent combination of decisions is very crucial; (ii) it is not difficult for engineers to predict how the activities relate with each other. It is usually the case that there are many possible combinations of activities that are internally coherent, and each engineer will still be able to reach one of them by making decisions based on history, customs, or what others are doing. However, there is in general only one best combination that is not only consistent internally but also match customer expectations well. This information concerning the globally optimal combination is not available to the engineers, as was discussed above. Furthermore, environments surrounding the automobile industry are now very volatile: consumer expectations are changing and ambiguous. These features that lead to missing information for reaching the solution are called innovative attributes. In addition, because of complementarities among activities, a small change in each activity could shift the globally optimal combination discontinuously from one combination to another. This is why the importance of the product manager's role as a concept infuser increases as integration to consumer expectations becomes more critical.

Note that in this story, the product manager's effort into engineering coordination itself is smaller under the heavyweight system than under the lightweight system: The distinguished role of the heavyweight product manager is not to coordinate engineers' activities directly but to ensure that autonomous engineering coordination reaches the right combination of activities in the set of internally coherent combinations. The lightweight product manager does not play this role, and hence more attention is allocated to internal coordination per se. The result is more specialization by engineers under the lightweight product manager system. How about the functional structure? Coordination under that system is through rules and procedures, detailed specifications, shared traditions among engineers, occasional direct contacts, and meetings (Clark and Fujimoto, 1991). Adaptation of product integrity to changing external environments appears to be nil. Therefore, flexible coordination across functional areas is not significant, and hence the highest degree of specialization emerges.

In this section, I have taken the so-called team theoretic approach where all the members of the organization are assumed to share its common goal. The main theme was the choice of 
organizational form in order to improve organizational decision making, from the perspective of limited rationality (imperfect communication and limited attention). Incentive issues were ignored in order to simplify the analysis. They are discussed in detail in the subsequent section.

\section{Incentives in Product Development Organization}

Womack et al. (1990) distinguish the best projects with heavyweight managers from other projects, in terms of the strength of control over the participants by the managers: In the former, "[the project members] retain ties to their functional department...but for the life of the program they are clearly under the control of the shusa [a typical Japanese word for product managers]. How they perform in the team, as judged by the shusa, will control their next assignment, which will probably be another development team." "In contrast, in most Western companies a development project consists of individuals, including the team leader, who are on short-term loan from a functional department. ... Key evaluations will come from the head of the employee's functional division..." (p. 114). The role of the heavyweight product manager appears to be not only gathering information to create concept and to coordinate, but also providing the members with strong incentives to cooperate for the success of the project.

Note that even the heavyweight product manager has no formal authority over participants. The formal boss of an engineer is the head of the functional department to which he belongs. Formal merit assessments are also conducted on functional basis. It is thus not clear how heavyweight product managers can motivate project participants. This paper does not offer any answer to this question. However, several case studies indicate that heavyweight product managers can in fact have participating engineers work for the projects. The citation from Womack et al. (1990) given above contains an example: Performance of the participating engineers in the project team affects their career. Or good product mangers can direct the project toward his goal simply by persuading and convincing the participants and functional managers. I hence assume that top management can design product development organization such that the product manager has strong influence over members. I also assume, as in the previous section, that top management itself cannot perform the role of the motivator, due to limited attention. 
Without a centralized incentive system for a project, incentives are largely provided through functional divisions. The degree of specialization in the project will then increase, because project engineers have little incentive to work with those from other divisions, and functional managers would like to limit the time they spend for the project so as to leave much time for functionally oriented tasks. The other direction is similar. If each engineer's activities are restricted to his narrow specialty area in a project, strong, product-oriented incentives will be unnecessary; incentives through functional division will suffice.

Although such a decentralized approach to incentives might be good in motivating each engineer to pursue a high level of functionality of cars within his specialty field, the priority of well-matched product integrity over specialized functionality in the today's auto industry will diminish the returns from such decentralized incentives drastically. Centralized incentives are crucial.

\subsection{Centralized incentives and broad task assignments}

Once the product manager obtains control over the members, the discussion in Section 3 offers several reasons why he may seek to induce the project engineers to engage in multiple activities possibly with job duplication; for example, design and testing of a door lock system are performed by a group of engineers rather than each engineer specializes in a narrow subtask of a small part of the system and hence more engineers in total perform the same set of tasks. The major factors are complementarities both across tasks and across engineers: an engineer's marginal productivity at one task increases as he does more at any other task or as the other engineers work more on the same task. Under this condition, a relatively low level of specialization saves incentive costs, and its relative benefits tend to dominate the costs, compared to highly specialized task assignments (see Section 3). Furthermore, the growing importance of product integrity reinforces the advantages of broad task assignments.

A perspective completely different from the discussion given above and in Section 3 provides another explanation of the relationship between the heavyweight product manager and a small degree of specialization. Note that the product manager does not have formal authority, and hence must spend considerable amount of time and energy to make engineers work for the project. Then if he finds engineers who are eager to exert efforts for the project, assigning them with broad responsibilities, rather than keeping them perform narrow tasks and attempting 
to find other engineers, will save time and energy of the product manager, and thus it is more efficient for the project as well.

The upshot is that the existence of the product manager as a strong motivator induces low levels of specialization in engineers. Without the centralized motivation mechanism, broad task assignments are not likely to emerge.

\subsection{The product manager's incentives}

I next turn to the product manager's incentives. The product manager appears to be a very demanding position. The job may bring extraordinary satisfaction, in particular, for those who love to make cars, while it is a position which requires personal sacrifices. What makes the product manager work so hard? I argue that the heavyweight product manager system itself provides the product manager with stronger incentives to invest in the project than the lightweight product manager system.

To this end, I interpret the heavyweight product manager system as the one in which top management delegates the control rights of the project as a whole to one product manager. In the lightweight product manager system, most of the control rights are left to top management and/or functional managers. In the functional structure, the control rights are dispersed among functional managers. Which distribution pattern of the control rights lead to more efficient decisions?

This modelling has been adopted by several economists in the context of integration versus non-integration. They emphasize the concept of incomplete contracts (see Williamson, 1985; Grossman and Hart, 1986; Holmstrom and Tirole, 1989). If parties can write comprehensive contracts which specify each side's responsibilities in all future contingencies, the organization structure, e.g., whether the project manager is heavyweight or lightweight, does not matter. If contracts are incomplete, responses to some future contingencies will be left unspecified because they are unforseen or it is too costly to prespecify what to do. Then if such an ex ante unforseen event actually occurs, the parties must negotiate. Bargaining is often costly, and hence the parties may want to specify how to resolve bargaining, e.g., who make decisions under unforseen contingencies. Specifying the allocation of residual control rights (which cannot be contracted explicitly) is one such example: Those who own the control rights can make decisions upon unforseen events. However, different allocation patterns of control rights 
lead to different ex post returns, and hence can affect the parties' ex ante incentives, in particular, to invest in relation specific assets.

Human assets appear to be the most important relation specific assets in product development. Managers should work hard to engage in understanding of new product concepts and problem solving. If all the control rights of the project are allocated to a product manager, as in the heavyweight product manager system, then the returns from investment will be fully appropriated by him, and hence his incentives to invest are very high. This explains why the product manager's investment will be higher under the heavyweight product manager system than under the lightweight system.

On the other hand, the heavyweight product manager system will attenuate the incentives of functional managers to work for the project, compared with the functional structure in which some of the control rights are allocated to the heads of functional departments. However, I can still argue that the system which realizes concentration of the control rights to the product manager will be superior from this viewpoint. The heavyweight product manager system has an advantage of providing strong incentives for the product manager. And because of the importance of product integrity, the product manager's incentives to invest in the project are crucial to the success of the project. Furthermore, the diluted incentives of functional managers under the heavyweight system may not be really a problem since the heavyweight product manager can directly contact with the engineers in each functional unit who participate in the project, and obtain control over the engineers' investment decisions by some sort of indirect incentive mechanisms.

\subsection{Heavier product managers?}

Although the heavyweight product manager has strong control over the behavior of participating engineers, the organization is still functional, and the engineers often work for other projects within their functional areas at a time. How can we understand this phenomenon? One obvious reason comes from technological considerations. If capable engineers are scarce resources, the firm will hesitate to disperse valuable engineers to different projects on a full-time basis. Such a project assignment will lose a lot of benefits from complementarities.

The incentive viewpoints offer another explanation. Engineers who are assigned with several projects are evaluated by different managers. Because projects are inherently team 
production, subjective evaluation by a manager is an important information source for the engineers' effort and ability. However, accompanying use of subjective information is two kinds of costs; influence costs, since the engineers will rationally spend unproductive resources to attempt to influence a manager's decisions to their favor, e.g., better task assignment, higher wages, higher status, and so on (see Milgrom (1988) and Milgrom and Roberts (1988) for formal analyses of influence activities); and costs from collusion and hidden gaming, since a manager may find it privately beneficial to treat some of his subordinates favorably or to demand some favor from each of them by threatening to favor others. Such behavior is costly to the organization as a whole (see Tirole (1986) and Laffont (1990) for the formal models).

It is argued that these costs restrict the use of subjective monitoring and hierarchical organizations inevitably acquire rule-oriented, bureaucratic features. However, the multiproject system can mitigate the problems. Influence activities will lose their effectiveness when there are several targets for such activities since influencing just one manager now has less returns and influencing several managers is costly. Collusion can be less costly because distorted monitoring information from a manager who colludes with an engineer can be checked by information supplied by other managers, and a larger coalition which involves several managers is much harder to sustain.

Considering careers of engineers and product managers yet offers other possible explanations. The firm wants to learn the engineers' abilities to improve task assignments and future promotion decisions. Suppose that an engineer performs several projects simultaneously. Some of them are research activities in the functional departments, others are product development projects of different kinds of cars. He may also perform different tasks in different projects. His performance in each project will then supply valuable information about various aspects of his potential ability. If assigning him with more than one project at a time is better in the learning perspectives, then the firm will not select the project execution team structure. ${ }^{3}$ In addition, performing multiple projects with great variety will offer important training opportunities to the engineers who may be promoted to the product managers.

\footnotetext{
${ }^{3}$ However, this conclusion is tentative. Recently Meyer (1991) analyzes a learning model of project assignments with team production. In her model, the multi-project engineer system is worse in terms of learning the engineer's ability, while it is better in terms of learning the product manager's ability.
} 


\section{Concluding Remarks}

Development of sophisticated new products such as autos requires large-scale coordination among a number of functions and components. It is obvious to expect that an effective project organization has a central unit such as a product manager who coordinates development activities across functional units. The best performing organization has more than that. The product manager there is "heavyweight" in that he has broader responsibilities, in particular, he is responsible for concept creation and its communication; he has direct access to the project members in each functional unit; and he has strong control over their decisions through some indirect incentive mechanisms.

Given the growing importance of product integrity relative to functionality in a few dimensions, centralization of concept creation and its direct communication with engineers are more effective. Centralization of the control rights over the members' human decisions provides stronger incentives to work for the success of the project, for both the members and the manager himself. And given such a more centralized structure, the members are induced to be less specialized in their task assignments: the product manager can then delegate coordination tasks to them who engage in productive interaction more effectively but with less incentive costs.

The paper has exclusively focused on product development organization of one project. It is however typical that in the firm several projects are in progress simultaneously. The analysis of multi-project organizations is an important future research topic. For example, the discussion in Section 5.3 suggests that one examine the possibility of an engineer engaging in multiple projects more carefully to understand the optimality of the heavyweight product manager system.

The paper closes with a final but important remark. The high performance of such a product development organization appears to be region-free. However, it is also true that most of them are Japanese. Can the "Japanese-style" system be easily adopted by Western projects as well? Or should they attempt to do so? Those who have studied product development in the auto industry, as well as the MIT Commission on Industrial Productivity, think that they should. However, it is also thought that it may not be easy to adopt the product development system alone: it is a part of a whole system and there could not exist one aspect without all 
the other (Aoki, 1992). I have the same opinion and point out a few aspects of the Western economy that might be against the introduction of the best product development organization analyzed in this paper.

First, it is said that, particularly in the U.S., an engineer's career is narrower and the success mainly depends on moving up through his functional specialty. ${ }^{4}$ Under this career pattern, decision making by engineers participating in a project will be strongly biased toward the interest of their functional divisions because they will have much longer relationship with their functional managers than the product manager. Furthermore, functional managers themselves may not have interests in cooperating product development projects under such a specialized career pattern.

This implies that the need for strong product managers is higher in the U.S. than in Japan. However, simply introducing the same heavyweight product manager system as that of Japanese auto makers may not work, because the product manager there has no formal authority to direct participating engineers. More explicit matrix organization or even the project execution team structure may be inevitable.

Second, more competitive labor markets in the West than in Japan may be relevant. The analysis of Prendergast (1991) suggests that when the labor market is competitive, senior managers may be reluctant to delegate much responsibility to a product manager because exerting more authority may improves their career prospects: For example, by carrying out many tasks, a senior manager may accumulate skills or discover his capability. ${ }^{5}$ Similarly, the competitive labor market may bias engineers investment toward specialization, because specialization into narrow tasks is likely to increase their visibility from the labor market.

Because of these additional elements, the optimal organizational form may not be identical between the West and Japan. The data in Clark and Fujimoto (1991) seem to show that the trend is in the same direction across regions. Although how far this change goes may be different among the U.S., Europe, and Japan, their data suggest that the analysis in the current paper be not far from pertinent.

${ }^{4}$ See for example Sakakibara and Westney (1985) who compare engineers' career in the computer industry in the US and Japan and obtain some supporting evidence.

5 Womack et al. (1990) report: "It's common in Detroit, Wolfsburg, and Paris for top management to override the team leader about the specifications and feel of the productoften repeatedly during the course of development." (p. 113). 


\section{References}

Aoki, M. (1986): "Horizontal vs. Vertical Information Structure of the Firm," American Economic Review, vol. 76, pp. 971-83.

(1988): Information, Incentives, and Bargaining in the Japanese Economy. Cambridge: Cambridge University Press.

(1992): "The Japanese Firm as a System of Attributes: a Survey and Research Agenda," CEPR Discussion Paper No. 288.

Asanuma, B. (1988): "Japanese Manufacturer-Supplier Relationships in International Perspective: The Automobile Case," Working Paper No. 8, Faculty of Economics, Kyoto University.

(1989): "Manufacturer-Supplier Relationships in Japan and the Concept of Relation-" Specific Skill," Journal of the Japanese and International Economies, vol. 3, pp. 1-30.

Bolton, P., And J. Farrell (1990): "Decentralization, Duplication, and Delay," Journal of Political Economy, vol. 98, pp. 803-26.

Clark, K. B., W. B. Chew, and T. Fujimoto (1987): "Product Development in the World Auto Industry," Brookings Papers on Economic Activity, vol. 3, pp. 729-71.

Clark, K. B., And T. Fujimoto (1991): Product Development Performance: Strategy, Organization, and Management in the World Auto Industry. Boston: HBS Press.

Dertouzos, M. L., R. K. Lester, R. M. Solow and the Mit Commission on InDustrial Productivity (1989): Made in America: Regaining the Productive Edge. Cambridge: The MIT Press.

Geanakoplos, J., And P. Milgrom (1991): "A Theory of Hierarchies Based on Limited Managerial Attention," Journal of the Japanese and International Economies, vol. 5, pp. $205-25$.

Grossman, S. J., And O. D. HART (1986): "The Costs and Benefits of Ownership: A Theory of Vertical and Lateral Integration," Journal of Political Economy, vol. 94, pp. 691-719.

Holmstrom, B., And P. Milgrom (1990): "Regulating Trade among Agents," Journal of Institutional and Theoretical Economics, vol. 146, pp. 85-105.

(1991): "Multitask Principal-Agent Analyses: Incentive Contracts, Asset Ownership and Job Design," Journal of Law, Economics, and Organization, vol. 7 (Special issue), pp. 24-52.

Holmstrom, B., and J. Tirole (1989): "The Theory of the Firm," in R. Schmalensee and R. D. Willig (eds.), Handbook of Industrial Organization. Amsterdam: North-Holland.

Iтон, H. (1988): "Information Structures, Task Structures, and Coordination Systems," Working Paper No. 4, Faculty of Economics, Kyoto University. $611-36$.

(1991): "Incentives to Help in Multi-Agent Situations," Econometrica, vol. 59, pp. 
(1992a): "Cooperation in Hierarchical Organizations: An Incentive Perspective," Journal of Law, Economics, and Organization, vol. 8, pp. 321-45. Economic Theory.

LAFFonT, J.-J. (1990): “Analysis of Hidden Gaming in a Three-Level Hierarchy," Journal of Law, Economics, and Organization, vol. 6, pp. 301-24.

Lincoln, J. R., And K. MCBRide (1987): "Japanese Industrial Organization in Comparative Perspective," Annual Review of Sociology, 13, 289-312.

Meyer, M. A. (1991): "The Dynamics of Learning with Team Production: Implications for Task Assignment," mimeo. Nuffield College.

Milgrom, P. R. (1988): "Employment Contracts, Influence Activities and Efficient Organization Design," Journal of Political Economy, vol. 96, pp. 42-60.

Milgrom, P., and J. Roberts (1988): "An Economic Approach to Influence Activities in Organizations," American Journal of Sociology, vol. 94 (Supplement), pp. S154-79.

Hall.

(1992): Economics, Organization and Management. Englewood Cliffs: Prentice-

Monden, Y. (1983): Toyota Production System: Practical Approach to Production Management. Norcross: Industrial Engineering and Management Press.

Prendergast, C. (1991): "A Theory of Worker Responsibility," mimeo. Graduate School of Business, University of Chicago.

Sakakibara, K., And D. E. Westney (1985): "Comparative Study of the Training, Careers, and Organization of Engineers in the Computer Industry in the United States and Japan," Hitotsubashi Journal of Commerce and Management, vol. 20, pp. 1-20.

Simon, H. (1976): "Applying Information Technology to Organization Design," reprinted in Administrative Behavior, Third Edition. New York: The Free Press.

Tirole, J. (1986): "Hierarchies and Bureaucracies: On the Role of Collusion in Organizations," Journal of Law, Economics, and Organization, vol. 2, pp. 181-214.

Williamson, O. E. (1985): The Economic Institutions of Capitalism: Firms, Markets, Relational Contracting. New York: The Free Press.

Womack, J. P., D. T. Jones, And D. Roos (1990): The Machine That Changed the World. New York: Rawson Associates. 